\title{
DETERMINATION OF PREFERRED ORIENTATION OF PYRITE IN A CHALCOPYRITE ORE BY MEANS OF NEUTRON DIFFRACTION
}

\author{
E. M. JANSEN, ${ }^{1}$ P. MERZ, ${ }^{2}$ H. SCHAEBEN,$^{3}$ W. SCHÄFER, ${ }^{2}$ H. \\ SIEMES $^{1}$ and G. WILL ${ }^{2}$ \\ ${ }^{1}$ Institut für Mineralogie und Lagerstättenlehre, RWTH Aachen, 5100 Aachen, \\ Germany \\ ${ }^{2}$ Mineralogisches Institut, Universität Bonn, Außenstelle Forschungszentrum \\ Jülich (KFA), 5170 Jülich, Germany \\ ${ }^{3}$ Laboratoire de Metallurgie des Materiaux Polycristallins (LM2P), Universite de \\ Metz, 57045 Metz, France
}

(Received January 10, 1992)

KEY WORDS Pyrite, Chalcopyrite, Neutron diffraction, Peak separation.

\section{INTRODUCTION}

In a project concerned with the development of preferred orientation in experimentally deformed chalcopyrite ores (Jansen, 1990) a few samples from the Frood Mine, Sudbury, were analysed by means of X-ray and neutron diffraction. The ore contains $55.0 \pm 9.2 \mathrm{wt} . \%$ chalcopyrite, $32.9 \pm 6.6 \mathrm{wt} . \%$ Pyrit, $12.1 \pm$ $9.0 \mathrm{wt} \%$ gangue and other minor minerals. Samples of $30 \mathrm{~mm}$ length and $15 \mathrm{~mm}$ diameter had been cored in the same orientation from the same handspecimen and deformed by axial compression.

\section{EXPERIMENTAL PROGRAM}

Measurements of preferred orientation of pyrite on cross-sections of the specimens by means of X-ray diffraction did not accomplish significant results. Therefore, the preferred orientation has been determined by means of neutron diffraction. Two specimens were selected: an undeformed one (CH50UV) and a specimen ( $\mathrm{CH} 5125)$ which had been strained to $14.2 \%$ under a confining pressure of $300 \mathrm{MPa}$, at a temperature of $300^{\circ} \mathrm{C}$ and a strain rate of $2.8 \times 10^{-6} \mathrm{~s}^{-1}$. The pole figures of the chalcopyrite- and pyrite-reflections were measured simultaneously (Figure 1) making use of a position sensitive detector (Will, Schäfer and Merz, 1989). The diffraction diagram of Figure 1 reveals overlapping of the pyrite and the chalcopyrite reflection peaks, with differences less than 1 degree in $2 \theta$ for (111) of pyrite with (112) of chalcopyrite and for (222) of pyrite with (312) 


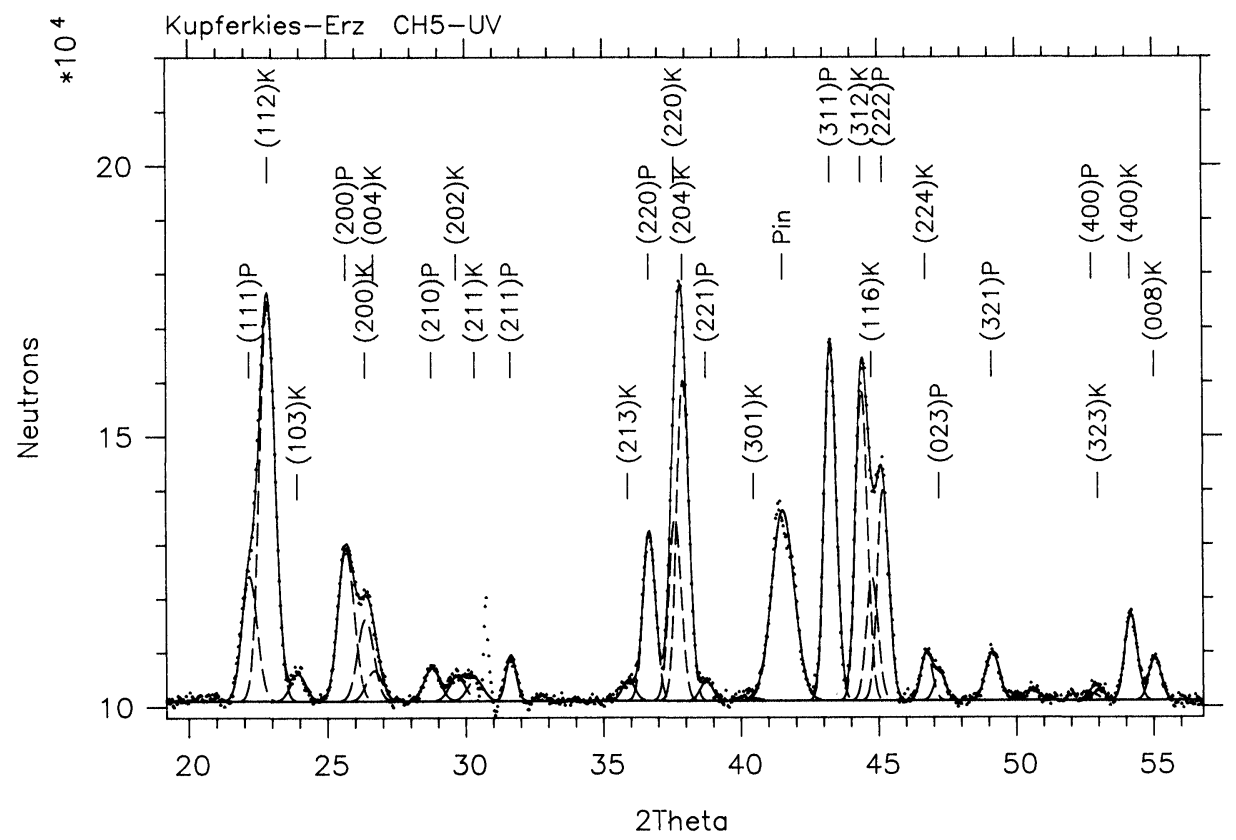

Figure 1. Profile analysis of the sum-diagram of the neutron diffraction of chalcopyrite of specimen CH50UV: $\mathrm{K}=$ chalcopyrite, $\mathrm{P}=$ pyrite.

and (116) of chalcopyrite. The major pyrite reflections (111), (200), (220) and the chalcopyrite reflections were resolved by means of a profile analysis method in order to obtain separated pole figures (Merz, Schäfer, Jansen and Will, 1991).

\section{QUANTITATIVE TEXTURE ANALYSIS}

The pole figures of the Figures 2 to 4 are intensity distributions of several planes of pyrite projected perpendicular to the specimen axis. The pole figures reveal a very weak preferred orientation, their densities deviate generally less than \pm 0.20 from the mean value. Only the (111)-pole figures expose larger deviations from the density 1.0. An interpretation of the preferred orientation in terms of the pole figures of the different reflections of the pyrite failed because the separation of its major reflections of pyrite (200), (220) and particularly (111) from their overlapping chalcopyrite reflections did obviously not succeed completely. This assumption was confirmed when the preferred orientation was represented in terms of odfs calculated from different combinations of reflections applying the maximum entropy program MENTEX (Schaeben, 1988, 1991). One odf was calculated from the three (200), (220), and (111) pole figures, another one by omitting the (111) pole figure from the two (200) and (220) pole figures only. Figure 2 shows the three measured pole figures (200), (220), and (111) of specimen $\mathrm{CH} 5125$ in comparison to the pole figures which were recalculated, resp. calculated from odfs. The (re)calculated pole figures of each reflection are 


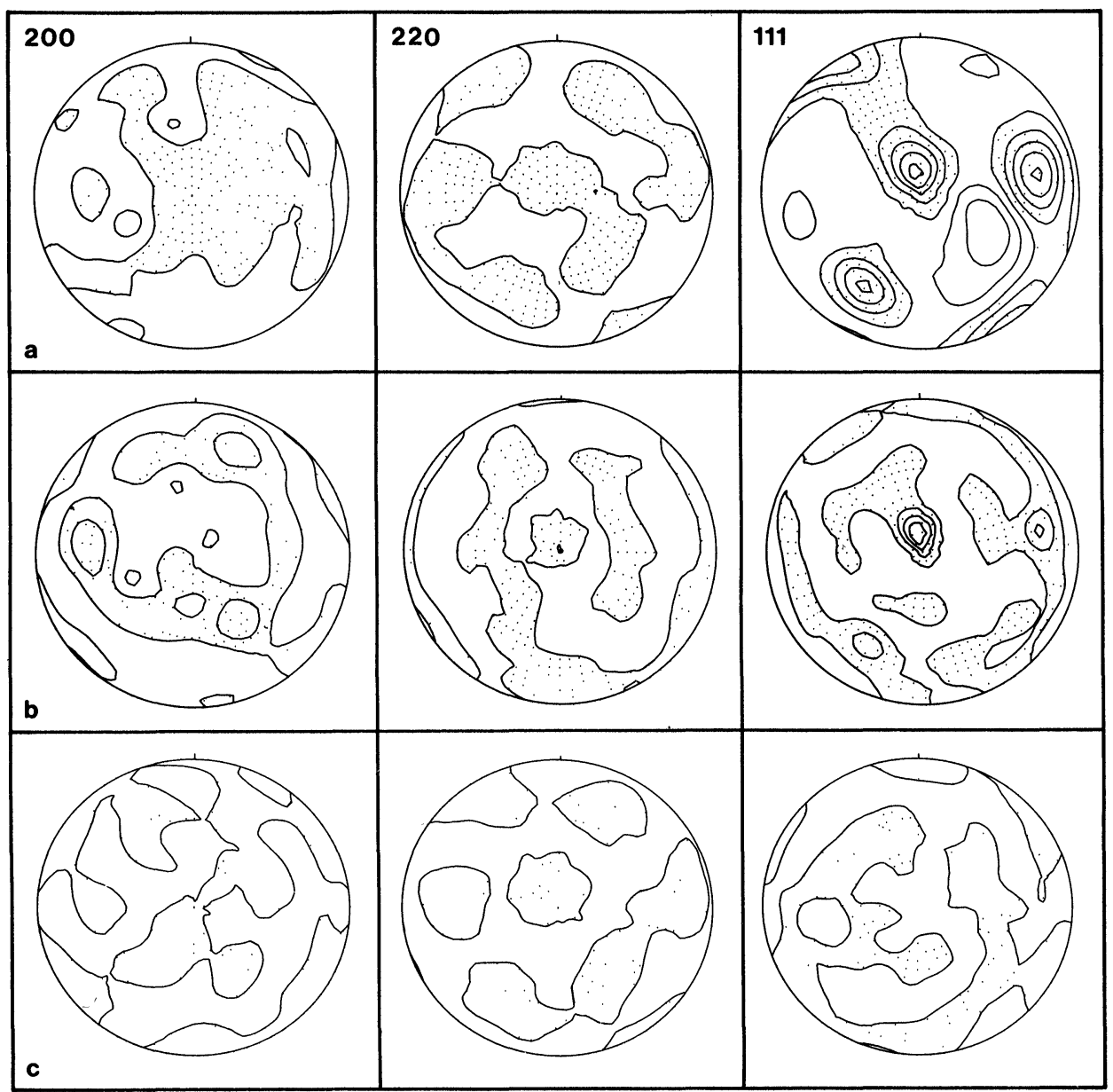

Figure 2. Pole figures of pyrite of the specimen $\mathrm{CH} 5125$. Dotted areas = densities below 1.0, Contour line distance 0.20 . (a) measured pole figures, (b) calculated pole figures using an odf derived from the three pole figures (200), (220) and (111), (c) calculated pole figures using an odf derived from the two pole figures $(200)$ and $(220)$.

mutually different and differ from the measured pole figure. The measured and (re)calculated pole figures agree only partially, a fact which is also indicated by the large RPO-values of Table 1. Especially the (111)-pole figure does not fit in with the other measured and calculated pole figures.

As Figure 1 shows, the (311)-reflection of pyrite is rather isolatedly situated between its neighboring chalcopyrite reflections and has a large intensity. Therefore, just the intensity data of the single (311) pole figure were used as input of the program package MENTEX and the other three pole figures were recalculated, resp. calculated. The agreement between the measured and calculated pole figures (311), (200) and (220) (Figure 3) is partially very good; in this case again, the calculated (111)-pole figure does not fit in with the measured 
Table 1 Calculation of the odf's by means of the maximum entropy texture program MENTEX.

\begin{tabular}{|c|c|c|c|c|c|c|c|c|c|c|c|}
\hline & \multicolumn{2}{|c|}{$\begin{array}{l}\text { odf } \\
\text { density }\end{array}$} & \multicolumn{2}{|c|}{$\begin{array}{l}\text { (111) pdf } \\
\text { denisty }\end{array}$} & \multirow[b]{2}{*}{$R P O$} & \multicolumn{2}{|c|}{$\begin{array}{l}(200) \text { pdf } \\
\text { density }\end{array}$} & \multirow[b]{2}{*}{$R P O$} & \multicolumn{2}{|c|}{$\begin{array}{l}(220) p d f \\
\text { density }\end{array}$} & \multirow[b]{2}{*}{$R P O$} \\
\hline & & $\max$ & min. & $\max$ & & $\min$. & $\max$. & & $\min$. & $\max$. & \\
\hline \multicolumn{12}{|c|}{$\begin{array}{l}\text { specimen CH5125PY: } \\
\text { ODF: } \quad(200),(220),(111): 22 \mathrm{i}\end{array}$} \\
\hline exp.: & & & 0.80 & 1.38 & & 0.89 & 1.08 & & 0.12 & 1.61 & \\
\hline calc.: & 0.09 & 2.51 & 0.61 & 1.27 & 9.5 & 0.77 & 1.13 & 5.3 & 0.23 & 1.20 & 21.2 \\
\hline ODF: & (200), & (220): & 22 iter & rations & & & & & & & \\
\hline exp.: & & & 0.80 & 1.38 & & 0.89 & 1.08 & & & & \\
\hline calc.: & 0.73 & 1.53 & 0.86 & 1.18 & 5.7 & 0.88 & 1.06 & 1.6 & & & \\
\hline ODF: & $(311)$ & 33: & \multicolumn{9}{|c|}{ iterations } \\
\hline exp.: & & & 0.91 & 1.11 & & & & & & & \\
\hline calc.: & 0.87 & 1.75 & 0.92 & 1.10 & 1.2 & & & & & & \\
\hline \multicolumn{12}{|c|}{$\begin{array}{l}\text { specimen CH50UVPY: } \\
\text { ODF: } \quad(200),(220), 22 \text { iterations }\end{array}$} \\
\hline exp.: & & & 0.81 & 1.23 & & 0.86 & 1.20 & & & & \\
\hline $\begin{array}{l}\text { calc.: } \\
\text { ODF: }\end{array}$ & $\begin{array}{l}0.80 \\
(311):\end{array}$ & $\begin{array}{l}1.71 \\
27 \text { ite }\end{array}$ & $\begin{array}{l}0.86 \\
\text { rations }\end{array}$ & 1.17 & 2.7 & 0.88 & 1.12 & 2.3 & & & \\
\hline exp.: & & & 0.95 & 1.09 & & & & & & & \\
\hline calc.: & 0.91 & 1.37 & 0.95 & 1.07 & 0.7 & & & & & & \\
\hline
\end{tabular}

exp.: experimental data, calc.: calculated data, RPO: mean absolute error in percent.

one. The preferred orientation is explained as a widely spread 'single crystal orientation' where (111) is oriented parallel to the specimen axis. The distribution of the poles of the single crystal orientation is given in Figure 3c.

Analysis of specimen CH50UV gave similar results as for specimen CH5125. Figure 4 shows the measured pole figures and for comparison the pole figures which have been calculated applying the odf derived from the measured (200)and (220)-pole figure data. As the RP0-values in Table 1 show, the result is again unsatisfactory. Therefore, the odf has been calculated from the measured intensities of the (311)-pole figure alone. In Figure 5 the measured and calculated pole figures are represented. In this case, the (311)-pole figure again seems to describe the main characteristics of the preferred orientation. The texture shows a 'single crystal orientation' with a (111)-maximum a little bit more excentric off the centre of the pole figure. The associated theoretical distribution of the poles is shown in Figure 5c.

The representations of the odfs (Matthies et al., 1990) and the calculation of model functions (Matthies et al., 1987, 1988, 1990) are omitted here because they are not considered essential but rather tedious.

\section{INTERPRETATION}

Comparing the conditions which were applied to deform the specimen $\mathrm{CH}$ 5125 with the conditions of the deformation experiments with pyrite by Cox et al. 


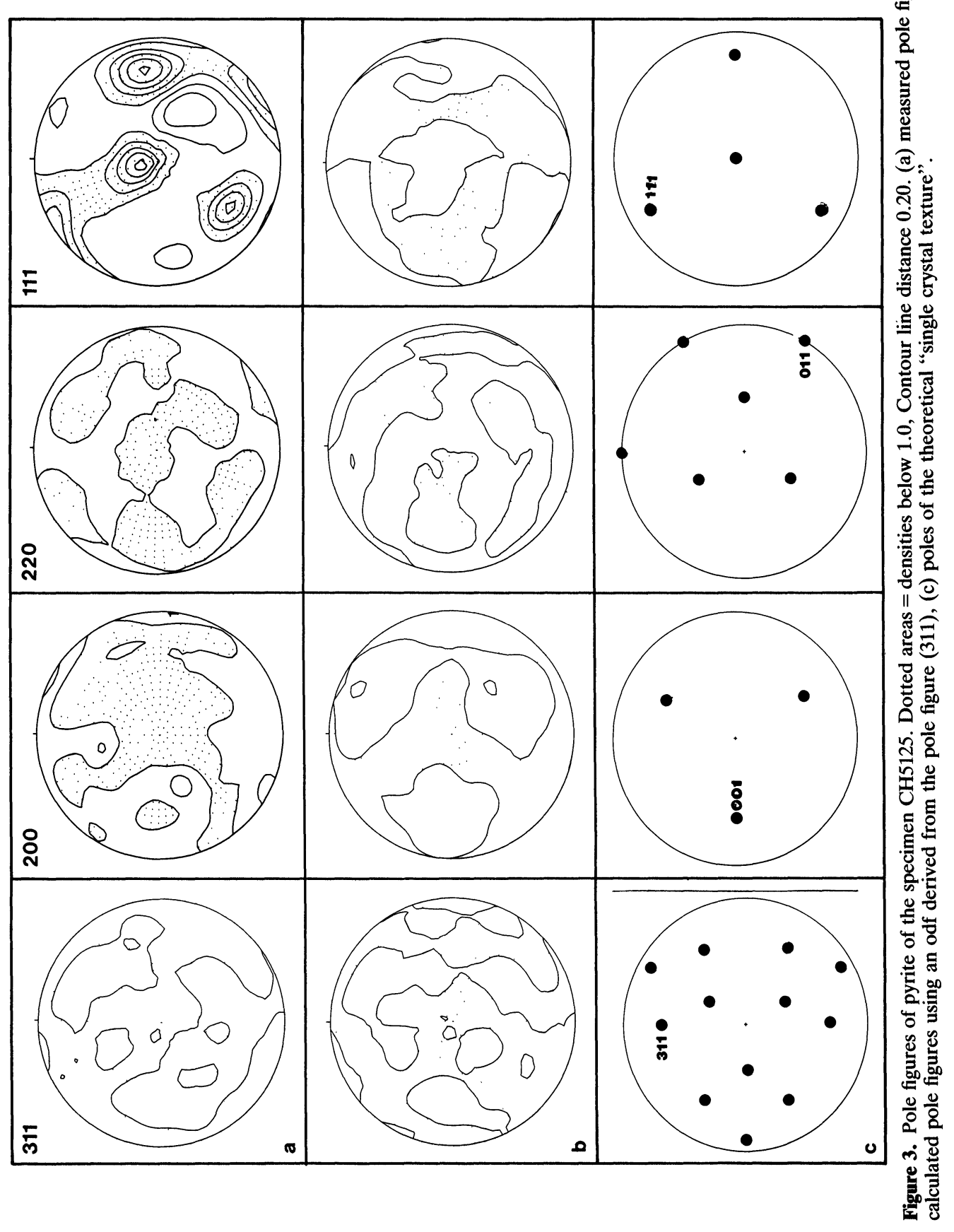




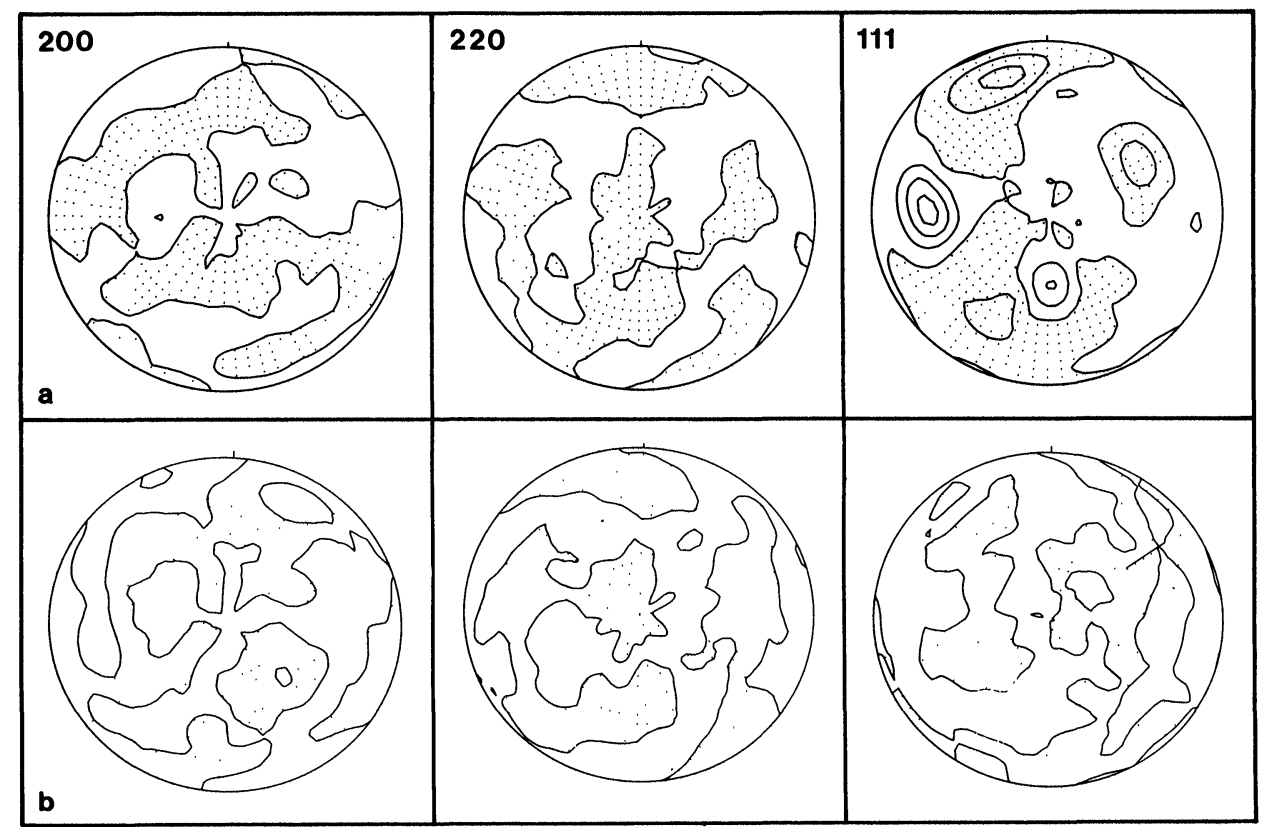

Figure 4. Pole figures of pyrite of the specimen CH50UV. Dotted areas=densities below 1.0, Contour line distance 0.20 . (a) measured pole figures, (b) calculated pole figures using an odf derived from the two pole figures (200) and (220).

(1981) it can be confidently concluded that plastic deformation of the pyrite of this specimen did not occur. The weak preferred orientation which has been observed in the undeformed specimen as well cannot be interpreted as deformation texture. In naturally deformed pyrite ores (111)-maxima have been described by v. Gehlen (1971) and Cox et al. (1992).

\section{CONCLUSIONS}

This communication emphasizes the difficulties when determining the texture of a minor component (pyrite) with a very weak preferred orientation in a multiphase sample, where its major phase (chalcopyrite) has a strong preferred orientation. The profile analysis method to separate overlapping reflections reaches its limits when the distance between the reflections is in the order of magnitude of the experimental halfwidths of the associated reflections. Applying the MENTEX algorithm, for which a single pole figure is sufficient, and calculating odfs was the crucial prerequisite to detect incompatibilities between the experimental pole figures, to identify the pole figures contaminated by the texture of the major phase and to omit them from analysis, and to achieve a rather simple consistent interpretation of the weak preferred orientation of the minor phase. 


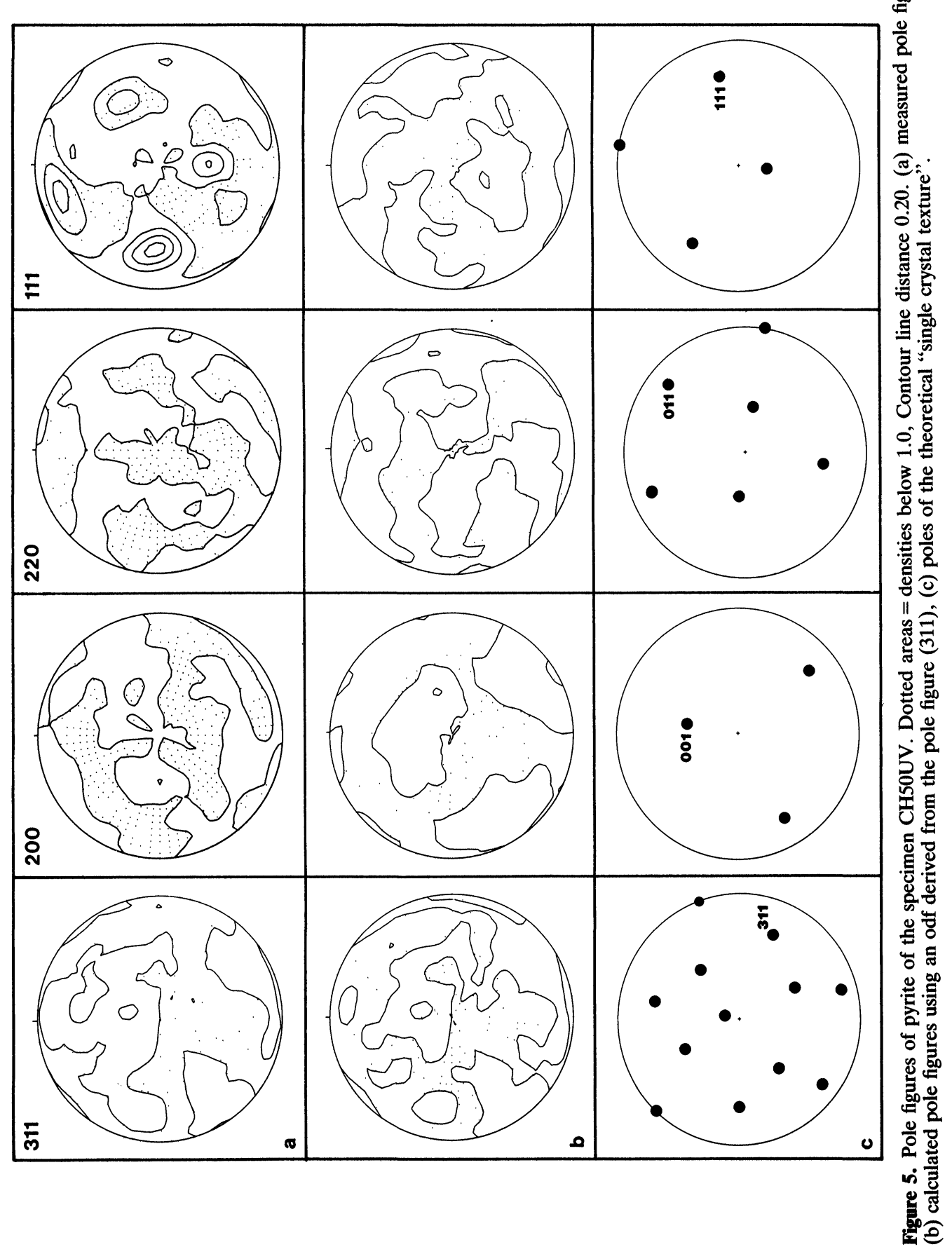




\section{ACKNOWLEDGMENT}

The authors (H. Sch.) acknowledge funding by a grant for proposition no. ERB4040PL900089 from the EC plan SCIENCE under contract no. ERBSC1*CT005001 and (E.M.J.) funding by the Deutsche Forschungsgemeinschaft, Bonn. Computing work was done with an IBM 3090 at the computer center of Aachen Technical University.

\section{REFERENCES}

Cox, S. F., Etheridge, M. A. and Hobbs, B. E. (1981). The Experimental Ductile Deformation of Polycrystalline and Single Crystal Pyrite. Econ. Geol., 76, 2105-2117.

Cox, S. F., Kunze, K., Merz, P., Schaeben, H., Schäfer, W., Siemes, H., Will, G. and Zilles, D. (1992). Preferred Orientation of Experimentally Deformed Pyrite Measured by Means of Neutron Diffraction, submitted to Mineralogical Magazine.

Gehlen v., K. (1971). X-Ray Analysis of Preferred Orientation of Ore Minerals-in particular with the Pole-figure Goniometer. Siemens Rev., 5th Spec. Issue, 38, 45-64.

Jansen, E. (1990). Experimentelle Deformation von natürlichem, polykristallinem Chalkopyrit bei Temperaturen bis $450^{\circ} \mathrm{C}$ und Verformungsraten von $10^{-5}$ bis $10^{-6} \mathrm{~s}^{-1}$ unter besonderer Berücksichtigung der entstehenden Texturen. Diss. RWTH Aachen, 148 p.

Matthies, S., Helming, K. and Kunze, K., 1990, On the Representation of Orientation Distributions in Texture Analysis by $\sigma$-Sections, I. General Properties of $\sigma$-Sections: phys. stat. sol. (b), v. 157, p. 71-83, II. Consideration of Crystal and Sample Symmetry, Examples. Phys. Stat. Sol. (b), 157, 489-507.

Matthies, S., Vinel, G. W., and Helming, K., 1987, 1988, 1990, Standard Distributions in Texture Analysis, Maps for the Case of Cubic-Orthorhombic Symmetry. Akademie Verlag Berlin, Vol. 1, p. 442, Vol. 2, p. 256, Vol. 3, p. 480.

Merz, P., Schäfer, W., Jansen, E. and Will, G., 1991, Neutron Diffraction Texture Analysis of Multiphase and Low Symmetry Materials Using Position-Sensitive Detector JULIOS and Peak Deconvolution Methods: Proceedings Ninth International Conference on Texture of Materials, Avignon, (eds. C. Esling, R. Penelle), Textures and Microstructures, 14-18, 65-71.

Schaeben, H., 1988, Entropy Optimization in Texture Goniometry, I. Methodology. Phys. Stat. Sol. (b), 148, 63-72.

Schaeben, H., 1991. Entropy optimization in quantitative texture analysis. II Application to pole-to-orientation density inversion. J. Appl. Phys. 69, 1320-1329.

Will, G., Schäfer, W., and Merz, P. (1989). Texture Analysis by Neutron Diffraction Using a Linear Position Sensitive Detector. Textures and Microstructures, 10, 375-387. 